\title{
Genotoxic and anti-proliferative effects of aminoguanidine on gamma- irradiated MCF-7 breast cancer cells.
}

\author{
Fonseca $^{\mathrm{a}}$ D.C., Ocampo ${ }^{\mathrm{b}}$ I.Z., Vieira ${ }^{\mathrm{a}}$ D.P. \\ ${ }^{a}$ Instituto de Pesquisas Energéticas e Nucleares, IPEN-CNEN/SP \\ Laboratory of Radiobiology/Center of Biotechnology, 05508-000, Sao Paulo, SP, Brazil \\ ${ }^{b}$ Universidad científica del sur \\ Av. Antigua carretera Panamericana Sur Km 19 Villa el salvador - Lima, Peru \\ dpvieira@ipen.br
}

\begin{abstract}
The intracellular production of nitric oxide is studied as a relevant phenomenon in exposure to ionizing radiation. There is evidence of local nitric oxide production in solid tumors. The study evaluated the effects of the administration of aminoguanidine, a selective inhibitor of an isoform of nitric oxide synthase on the frequency of genotoxic damage, loss of clonogenic potential and induction of cytotoxicity after exposure of human breast tumor (MCF7) cells to ionizing radiation in radiotherapeutic doses. Cells were treated with aminoguanidine (1 or $2 \mathrm{mM}$ ) and irradiated by gamma radiation at doses between 0.5 and 8Gy. In cultures treated with $1 \mathrm{mM}$, we observed increased cytotoxicity and genotoxicity, and reduction of the clonogenic potential of the colonies. Alternatively, $2 \mathrm{mM}$ aminoguanidine produced the opposite effect, apparently protecting cultures from the effects of exposures. The experiments suggested that the administration of aminoguanidine may reduce the in vitro radiosensitivity of tumors due to the increase of the frequency of genotoxic damage.
\end{abstract}

Keywords: nitric oxide, radiation, breast cancer. 


\section{INTRODUCTION}

Production of free radicals and oxidizing species by ionizing radiation in aqueous media is a well-known characteristic of exposures. The production of reactive oxygen (ROS) and nitrogen (RNS) species comprises a set of phenomena whose scope may include effects on DNA molecules [1], blockade of cell division [2], activation of necrosis pathways [3] and nitrosylation of proteins [4]. Studies aimed at understanding the bystander effects of radiation suggested that the damage from ionizing radiation transcends the paradigm linking cell death strongly to breaking of DNA strands, [5], and more recent papers evaluating the effects of anti -and pro -oxidant molecules discuss the central role of RNS in certain pathologies, including cancer $[6,7]$.

From this point of view, the production of RNS would be as or more harmful than the ROS, once the body has a greater variety of defenses against oxidative radicals (such as peroxidases), than against reactive nitrogen species [3]. Nitric oxide (NO) produced by nitric oxide synthases as well as exogenous NO donor drugs increase the radiosensitivity of hypoxic tumor cells via reduction of hypoxia through increased tumor perfusion [5], and it was suggested that NO is a more potent radiosensitizer than oxygen [8]. Moreover, it was observed toxicity of NO due both to itself than with the NO oxidizing reactive derivatives. The modest toxicity of $\mathrm{NO}$ is increased by fast connections between $\mathrm{NO}$ and $\mathrm{O}_{2}^{-}$, forming $\mathrm{ONOO}^{-}$ (peroxynitrite), which is a more potent oxidant with toxic and nitrosative properties proteins, which may produce greater pathological consequences [9]. Therefore, it is difficult to identify the specific role of NO in carcinogenesis because it is dependent on its concentration, interaction with other free radicals, metal ions and proteins, as the cell type and genetic background.

NO can both cause damage to DNA and protect from cytotoxicity, can inhibit and stimulate cell proliferation and can be both pro and anti-apoptotic $[10,11]$. Aminoguanidine, a specific inhibitor of nitric oxide synthase 2 (NOS2) [12] was used in cell cultures of human breast tumor (MCF7) in order to observe cytotoxicity, alterations on clonogenic potential and genotoxicity in experimental situations in which the balance of NO production has been changed. 


\section{MATERIALS AND METHODS}

\subsection{Cell Culture and solutions}

Human breast adenocarcinoma cells (MCF-7, ATCC\# HTB-22) were maintained in $25 \mathrm{~cm}^{2}$ flasks with RPMI 1640 (Gibco®, Grand Island, NY) medium supplemented with $10 \%$ fetal bovine serum (GIBCO- United states) and antibiotics mixture (1\% penicillin / streptomycin, (GIBCO, Grand Insland, NY) until 60-70\% confluency. All incubations and propagation of cells were carried out in a humid and controlled atmosphere $\left(37^{\circ} \mathrm{C} ; 5 \% \mathrm{CO}_{2}\right)$. After thawing, cells were kept growing for no more than 10 sub cultivation steps. When required, cells were washed using PBS with EDTA (5mM) and trypsinized (trypsin 0,5\%). Using trypan blue exclusion test, only viable cells were used in experiments.

\subsection{Aminoguanidine $\mathrm{IC}_{50 \%}$}

Tripsinized cells were suspended in culture medium, and aliquots were assayed for viable cell concentration using trypan blue exclusion test in a hematocytometer under microscope observation. Cells were seeded on 96-well plates (5000 viable cells / well in $200 \mu \mathrm{L}$ ) and were allowed to adhere for 24 hours. Medium from wells was replaced by fresh media (blank and cell control wells) or with increasing concentrations of aminoguanidine hydrochloride (Cat.\#396494, Sigma-Aldrich, St.Louis, MO,) dissolved in medium. One set of experiments assayed cytotoxicity in cultures treated with a $1-10 \mathrm{mM}$ range, in increments of $1 \mathrm{mM}$. Another set of experiments tested a $10-100 \mathrm{mM}$ range, in $10 \mathrm{mM}$ increments. Each concentration was tested in octuplicates, and three plates per set were tested (1-10mM or 10-100mM). After incubation for 24 hours, media was removed from wells and cells were washed in sterile PBS $\left(37^{\circ} \mathrm{C}\right)$. After PBS removal, wells received $200 \mu \mathrm{L}$ of viability assessment reagent mixture, containing culture media, MTS (CellTiter 96® AQueous MTS Reagent Powder, Promega Corporation, Madison, WI, USA) and PMS (Sigma-Aldrich, Street Saint Louis, Missouri, USA), following manufacturer protocol. After 2 hours of incubation, plates were analyzed using 490nm absorbance values collected in an appropriate plate reader (Multiskan EX, 
Labsystems). Values were corrected to remove baselines from blank cell wells. Corrected values were given in percentages relative to controls from both experiment sets and were compiled and fitted to a sigmoidal dose-response model to calculate $\mathrm{IC}_{50 \%}$ of aminoguanidine in MCF-7 cells.

\subsection{Cell viability assay}

To test if aminoguanidine could induce cell toxicity in irradiated cells, cell suspensions from untreated and treated with 1 or $2 \mathrm{mM}$ of aminoguanidine in medium for 24 hours prior to irradiation were irradiated at increasing doses $(0.5,1,2,4,8 \mathrm{~Gy})$ of gamma radiation using a ${ }^{60}$ Co source (GAMMACELL 220 - Irradiation Unit of Canadian Atomic Energy Commission, Ltd.) at Center of Radiation Technology (CTR) of Nuclear and Energetic Nuclear Institute (IPEN/CNEN-SP) using a lead attenuator (90\% of attenuation). Cells were washed, suspended in culture medium, assayed for viable cell concentration as described above and seeded (5000 viable cells / well in $200 \mu \mathrm{L}$ ) in 96-well plates. Cultures received same MTS mixture as for $\mathrm{IC}_{50 \%}$ experiments 48 hours after irradiation and analyzed as described previously.

\subsection{Micronucleus frequency in binucleated cells}

Genotoxicity tests using micronucleus frequency in binucleated cells (BNC) were performed using a modified protocol. Conventional microscopy glass slides were cut into $40 \mathrm{x}$ $25 \mathrm{~mm}$ pieces, washed and sterilized to further use in cell culture conditions. To prepare the experiment, glass pieces were placed inside plastic Petri dishes $\left(6 \mathrm{~cm}^{2}\right)$. Cells $\left(500 \mu \mathrm{L}, 6 \times 10^{4}\right.$ cells $/ \mathrm{mL}$ ) were seeded in duplicates only on cut slides and let to adhere for 24 hours. After this time, slides were washed once with phosphate buffered saline solution (PBS) and $4 \mathrm{~mL}$ of culture medium was added to plates. All further experimental procedures were carried using adherent MCF7 cells on slides. After incubation for 72 hours, cells were treated or not with 1 or $2 \mathrm{mM}$ of aminoguanidine. Treatment was carried out by 24 hours. Cells were washed once in PBS $\left(37^{\circ}\right)$ and irradiated in fresh PBS using same conditions used for the clonogenic potential assays, but at doses not greater than $2 \mathrm{~Gy}$. After irradiation, PBS was removed and cells in 
slides received culture media with $4 \mu \mathrm{g} / \mathrm{mL}$ of cytokinesis blocker (Citochalasin B; SigmaAldrich, Sao Paulo, Brazil) and incubated for 72 hours. Cells were then washed in PBS as described and fixed by incubation with $4 \%$ formaldehyde in PBS for 15 minutes at room temperature. Fixed cells were washed three times in PBS to remove excess formaldehyde and let dry in room temperature. Just before microscopic visualization, fixed cells on slides received $50 \mu \mathrm{L}$ of acridine orange (Sigma-Aldrich, Sao Paulo, Brazil) solution $(0.000015 \%$ w/v in sterile PBS), covered with proper coverslips and incubated for 1 minute at room temperature. Glass pieces with stained cells and coverslips were mounted on top of conventional glass slides and visualized through fluorescence microscopy (Nikon 80i) using convenient filter block (Excitation: 450-490nm; Emission: 515nm). In this configuration, acridine orange in citoplasms fluoresced in bright red color, and DNA in nuclei and micronuclei emitted a strong green fluorescence. Only binucleated cells were considered in this study. A minimum of 1000 events (binucleated cells, exhibiting or not micronuclei) were counted per slide. Scores of binucleated cells $(\mathrm{BN})$ with one or more than one micronucleus were analyzed. Counts were converted as percentages of total binucleated cells and plotted in bar graphs.

\subsection{Survival fractions}

For clonogenic potential assessment, cells were tripsinized and suspended in PBS for irradiations following above description. Cultures with 1 or $2 \mathrm{mM}$ of aminoguanidine were treated for 24 hours before irradiations. Suspensions were seeded (300 viable cells / plate in 3mL) in $6 \mathrm{~cm}^{2}$ plastic Petri dishes in triplicates and inspected daily until colonies in control plates showed at least 50 cells / colony. At this time (12-14 days), medium was removed from plates and cells were washed in PBS $\left(37^{\circ} \mathrm{C}\right)$ for 5 minutes. After PBS removal, cells were fixed with methanol at room temperature for 30 minutes and stained by Giemsa (Sigma-Aldrich, Street Louis, MO, USA) in phosphate buffer. Stained colonies were manually counted. Data was first adjusted for plating efficiency (PE), and values were given as percentage of controls, then fitted to an exponential growth model to show mortality plots of survival fraction (SF) values, or to a sigmoidal dose-response model to test whether aminoguanidine treatment could change $\mathrm{LD}_{50 \%}$ values. 


\subsection{Calculation methods and statistical analysis}

$\mathrm{IC}_{50 \%}$ from microplate assays and $\mathrm{LD}_{50 \%}$ values from survival fraction experiments were fitted to the sigmoidal dose-response equation

$$
\mathrm{Y}=100 /(1+10((\log \mathrm{IC} 50-\mathrm{X}) * \mathrm{H})))
$$

, where survival fraction values were represented by "Y" and dose values were inputs of "X".

“Log IC50" and "H" (hillslope) values were calculated from data. For $\mathrm{LD}_{50 \%}$ experiments, calculated LD50 values from untreated or treated ( 1 or $2 \mathrm{mM}$ of aminoguanidine) were compared using extra-sum of squares F-test to determine if treatment could induce statistically significant $(\mathrm{p}<0.05)$ changes of radiosensitivity based on $\mathrm{LD}_{50 \%}$ values. Percentages of binucleated cells (BNC) with micronuclei (MNBNC), with a single (SMNBNC) or multiple (MMNBNC) micronuclei from treated and irradiated cultures were tested to assess statistically significant $(\mathrm{P}<0.05)$ differences using two-way ANOVA and Bonferroni post-tests as described. MNBNC percent from untreated cultures were fitted to a quadratic model to help evaluation whether method modifications could interfere in results. Plating efficiency of cells in SF experiments were calculated using the formula $\mathrm{PE}=$ (counted colonies) / (seeded cells) $\mathrm{x}$ 100. Plating efficiency values were expressed in percentages of controls (unirradiated and untreated cells) and these values were used to calculate SF using the formula: SF = counted colonies in a treated culture / seeded cells $\mathrm{x}$ (control PE). Finally, values were fitted to the model

$$
\mathrm{Y}=\mathrm{e}^{\left[-\left(\mathrm{A}-\mathrm{B} * \mathrm{X}-\mathrm{C} * \mathrm{X} \mathrm{X}^{\wedge}\right)\right]}
$$

where SF values were represented by "Y" and radiation doses by "X". "A", " $B$ " and "C" fit coefficients (independent, linear and quadratic, respectively) from untreated and treated cultures were also tested by F-test as described. Unfitted SF values were compared using twoway ANOVA and Bonferroni post-tests, and were considered different if $\mathrm{p}<0.05$.

All analyses were performed using Prism7 (GraphPad Prism, San Diego, California, USA) software. 


\section{RESULTS AND DISCUSSION}

\subsection{Aminoguanidine $\mathrm{IC}_{50 \%}$ and choice of subsequent concentrations}

The present work chose to use aminoguanidine as a NO production inhibition due to its selectivity to reduce only the nitric oxide synthase-2 activity [9]. After fitting of data $\left(\mathrm{R}^{2}\right.$ : $0,9503)$, analysis of decreases of relative cell growth could show that aminoguanidine reduced relative cell growth in $50 \%$ if used at a $22.6 \mathrm{mM}$ concentration (Figure 1). This value was used to set aminoguanidine concentrations for subsequent experiments, as 1 and $2 \mathrm{mM}$ did not induced statistically significant cytotoxicity in cultures (data not shown). Value of inhibitory concentration was found to be consistent to other works [12,13], and allowed to proceed experimentation of non-citotoxic concentrations.

Figure 1: Relative-to-control cell growth $\left(G_{R E L}\right)$ of $M C F 7$ cultures treated with increased concentrations of aminoguanidine. IC $C_{50 \%}$ was calculated as $22.6 \mathrm{mM}\left(\log I C_{50 \%}=1.354\right)$. Bars in data points represent SEM.

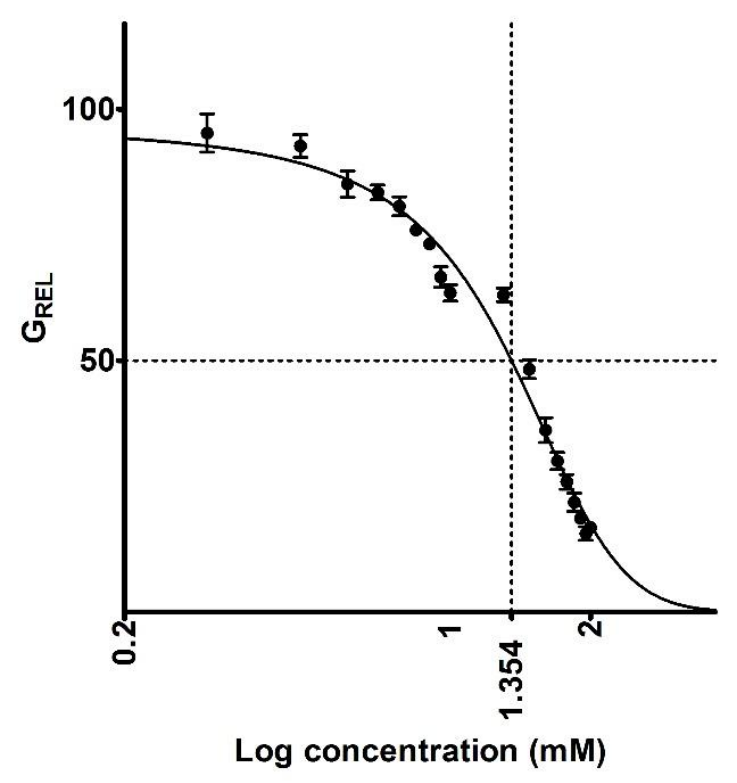


Aminoguanidine administration could induce significant differences in cell toxicity on irradiated cells: Treatment with $1 \mathrm{mM}$ of aminoguanidine reduced significantly $(\mathrm{p}<0.01)$ cell viability 48 hours after irradiation when cultures were irradiated with $0.5 \mathrm{~Gy}$, compared to non-treated control irradiated with same dose. In cultures treated with $2 \mathrm{mM}$, cell viability showed reduction $(\mathrm{p}<0.01)$ only on those irradiated with 8Gy (Figure 2). Aminoguanidine administration, and thus reduction of intracellular NO amount was found to be a radiossensitizing factor as in other works [14-16], in a contrary notion that NO production inhibition could prevent animal models [17] or cells [18] from radiotoxicity. Its effect was related to induction of DNA double-strand breaks (DSB) in non-irradiated bystander cells [1].

Figure 2: Effects on MCF7 cell viability upon aminoguanidine administration combined with gamma-radiation. Cultures treated with increased concentrations of aminoguanidine and/or radiation doses. (०): $p<0.01$. Comparisons to untreated controls irradiated at same dose. Bars in columns represent SEM.

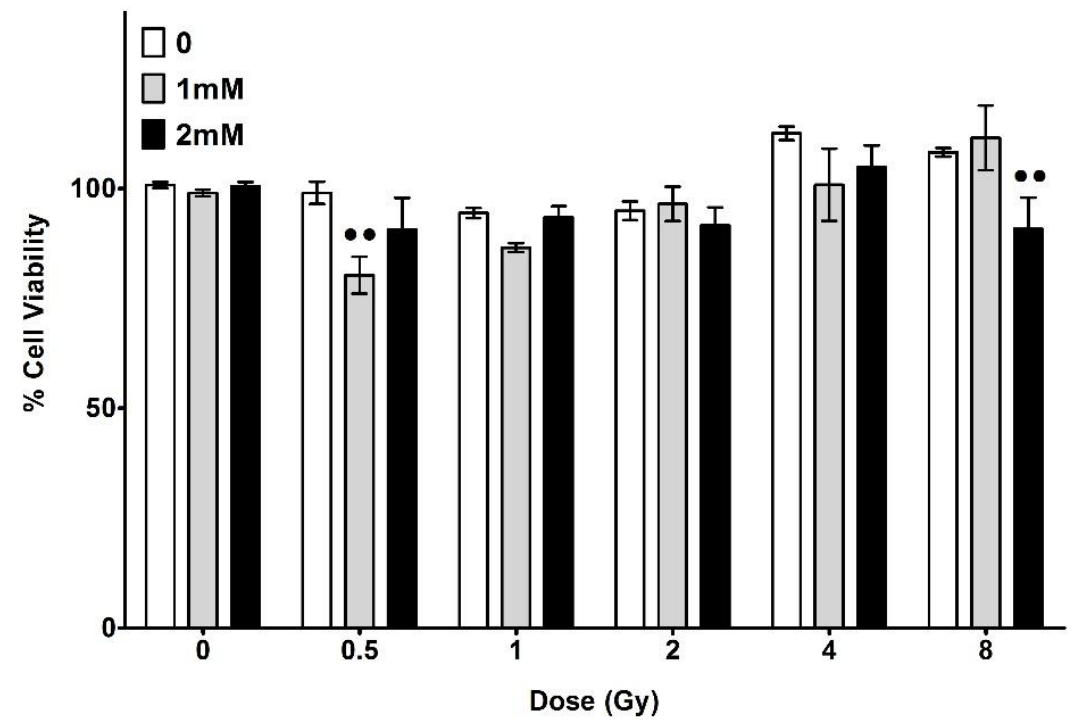

Although there are certain experimental designs that allow some equivalence between the results obtained from cytotoxicity and clonogenic potential assays [19], it is widely accepted that clonogenic potential assays better describe the antiproliferative effects of ionizing 
radiation [20]. Nevertheless, there is a need to highlight any effects of the administration of the nitric oxide synthase inhibitor on the viability of the irradiated cells, as shown in Figure 2.

\subsection{Micronuclei frequencies from treated groups are different compared to controls}

Modifications of the protocol of quantification of micronucleus in cytokinesis-block assays were tested prior to statistical analysis of data. Binucleated cells and micronuclei inside cytoplasms could be well distinguished upon acridine orange staining, and grouped cells could be localized in a fast manner in slides (Figure 3). Percentages of total number of BNC bearing micronuclei obtained in irradiated controls (untreated) were fitted to a quadratic model as used for analysis of genotoxic effects of ionizing radiation, $\left(\mathrm{R}^{2}: 0.9988\right)$, suggesting that modifications in technique could preserve the quadratic nature of observed response (Figure 4). It was used a well-known staining method [21-24] for MN scoring, with some modifications regarding the method of cell culture. In this work, we report results from preparations cultured, fixed, stained and analyzed directly on microscopic evaluation substrates (coverslips). Traditional preparation methods [25] could tend to overspread BNC's, potentially increasing scoring time. Thus, cells could be more easily analyzed if laid on slides through centrifugation [26]. The proposed discrete modifications did not interfere with expected results when fitting data from irradiated ( 0 to $2 \mathrm{~Gy}$ ) cultures to a linear-quadratic response model (Figure 4), showing good relationship to classic preparation methods. 
Figure 3: MCF7 (control culture) binucleated cells observed under fluorescence microscopy after acridine orange staining. Binucleated cells (+) and one micronucleus in binucleated cell (*) can be observed. Image acquired under 40x magnification.

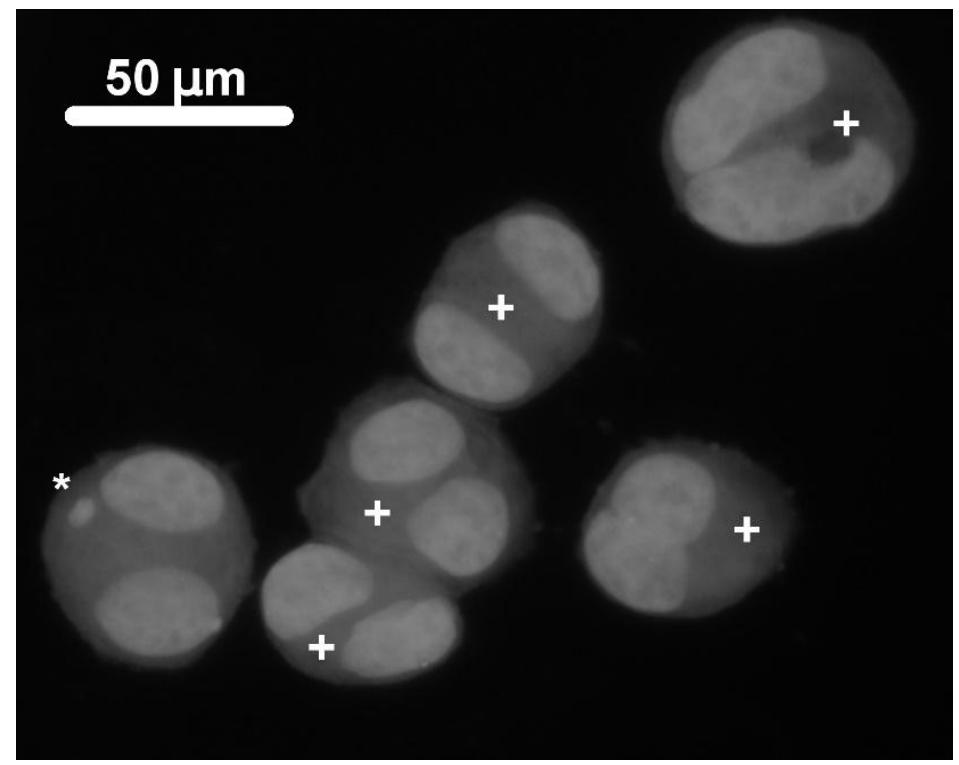

Figure 4: Quadratic response of percentage of binucleated cells with micronuclei (\% $M N B N C)$ in untreated MCF7 cells irradiated at indicated doses. Bars in data points represent SEM.

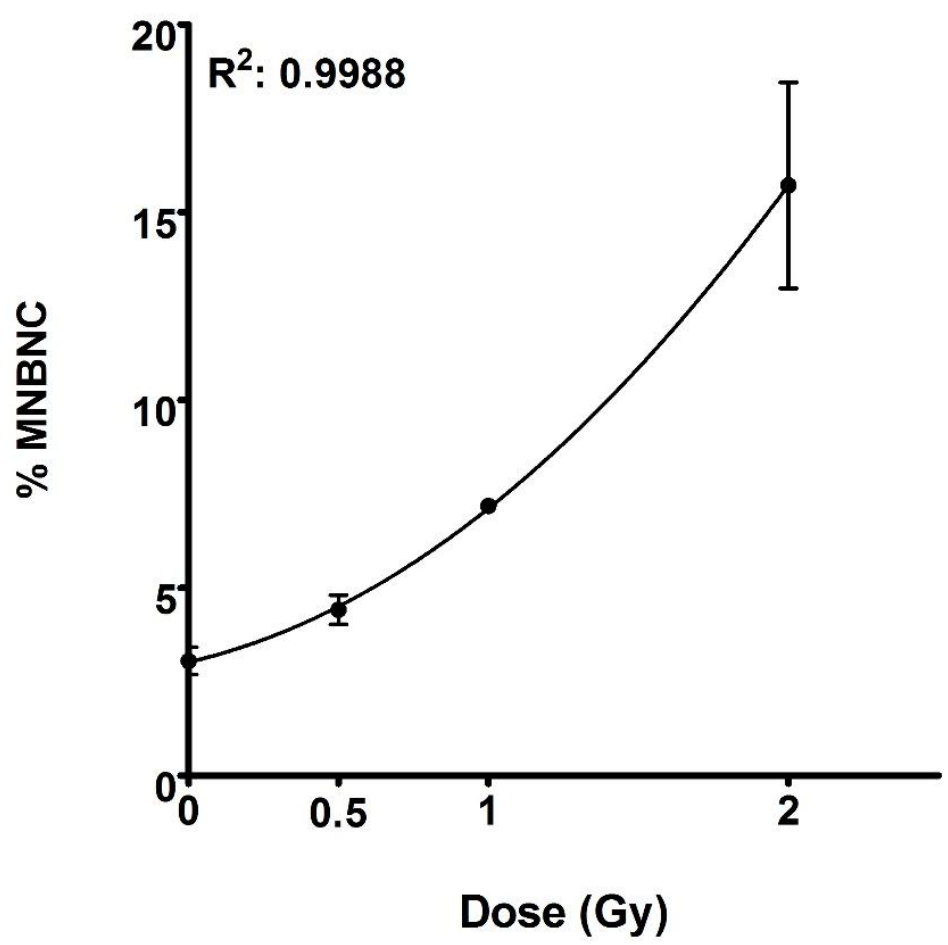


Significant differences between controls and groups treated with $1 \mathrm{mM}$ of aminoguanidine were observed. Those cultures showed an increase in total percent of BNC with micronuclei (\% MNBNC) and percent of BNC with only one micronucleus (\% SMNBNC) (Figures 5a and $5 b$ ) in some doses. Alternatively, treatment with $2 \mathrm{mM}$ reduced significantly total percent of BNC with micronuclei and with multiple micronuclei inside cytoplasm (\% MMNBNC) in cultures irradiated at 2Gy (Figures 5a and 5c). A broader view of this experiment could suggest that $1 \mathrm{mM}$ treatment induced radiosensitivity, and $2 \mathrm{mM}$ treatment could protect cells from genotoxic damage, especially at $2 \mathrm{~Gy}$ dose. Other works showed a biphasic response of nitric oxide synthase (and nitric oxide production) inhibition on radioinduced DNA lesions [27] by dicentric chromosome frequency assay. The micronucleus frequency test used in this work could show results in concordance.

Figure 5: Micronuclei frequency in cultures untreated or treated with 1 or $2 \mathrm{mM}$ of aminoguanidine and irradiated at indicated doses. (a) Percentage BNC with micronuclei given in percent of binucleated cells $(M N B N C)$. (b) Percentage of BNC with only one micronucleus (SMBNC). (c) Percentage of BNC with more than one micronucleus (MMBNC). (๑):

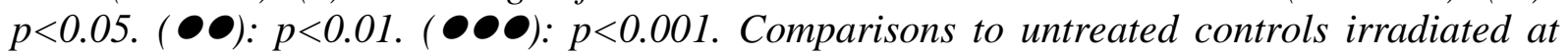
same dose. Bars in columns represent SEM.
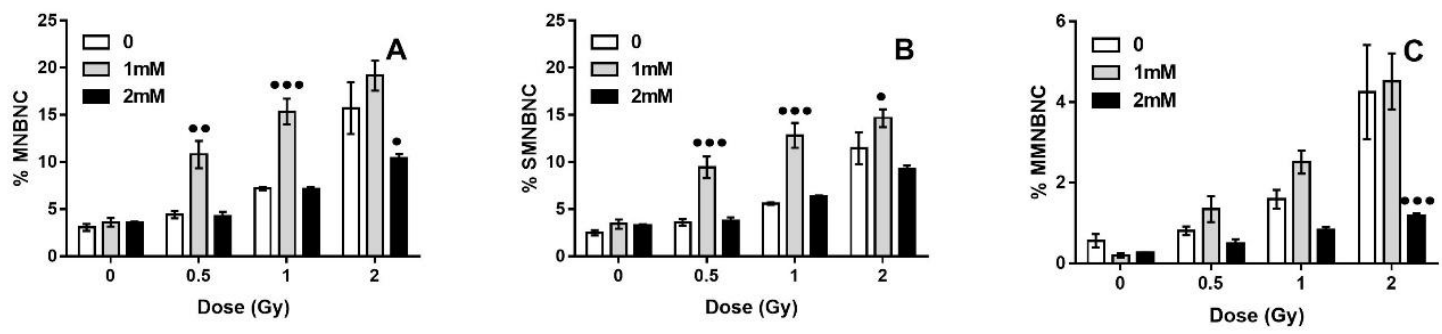

\subsection{Aminoguanidine induced significant differences in survival fractions fits to exponential growth model}

Fits of survival fraction data from experiments were shown in Figure 6. Goodness of fit coefficients (R2) were 0.9652 for untreated (0), 0.9719 and 0.9985 for cultures treated with 1 and $2 \mathrm{mM}$, respectively. F-tests to compare fit coefficients showed significant difference 
$(\mathrm{p}=0.043)$ in " $\mathrm{B}$ " coefficient (linear component) values when analyzing all groups, but groupto-group comparison did not show differences ( $\mathrm{p}>0.05$ ). Alternatively, two-way ANOVA could show significant differences $(\mathrm{p}<0.01)$ in found variances. Also, Bonferroni post-test could show difference $(\mathrm{p}<0.01)$ between cultures treated with $1 \mathrm{mM}$ and irradiated by $0.5 \mathrm{~Gy}$ and untreated controls irradiated at same dose, and difference $(\mathrm{p}<0.05)$ between 1 and $2 \mathrm{mM}$ treated cultures irradiated at 0.5 Gy (Figure 7). Only cells from non-treated cultures (NT) developed into colonies, with a very low frequency not observed on graph. When irradiated by $0.5 \mathrm{~Gy}$, cultures treated with $1 \mathrm{mM}$ showed significant reduction on SF. Increased NO concentrations could be related to apoptosis inhibition and thus, relative increase of cell survival on MCF7 non-irradiated cells as found in other works [28]. Decreases in survival fractions form $1 \mathrm{mM}$-treated cultures could be related to remarkable genotoxic found in those cultures, as assayed by micronucleus frequency test.

Figure 6: Survival fractions $(S F)$ from cultures untreated $(0)$ or treated with 1 or $2 \mathrm{mM}$ of aminoguanidine and irradiated at indicated doses. Bars in data points represent SEM.

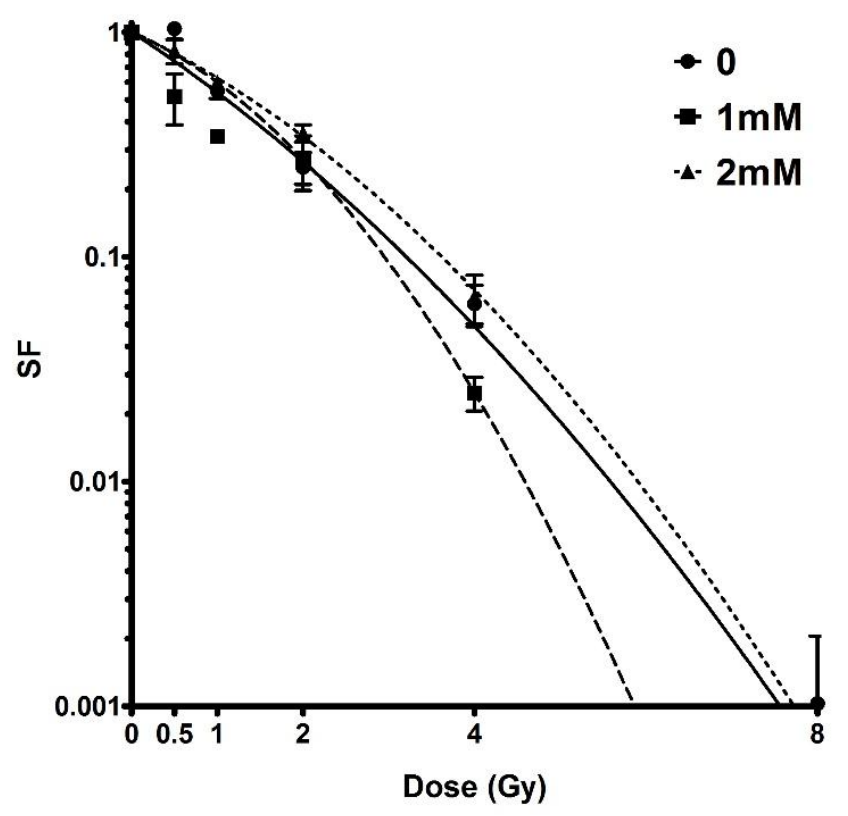


Figure 7: Survival fraction (SF) data from experiments of clonogenic potential assessment, columm plotted. (०००): $p<0.001$. Comparisons to untreated controls irradiated at same dose. Bars in columns represent SEM.

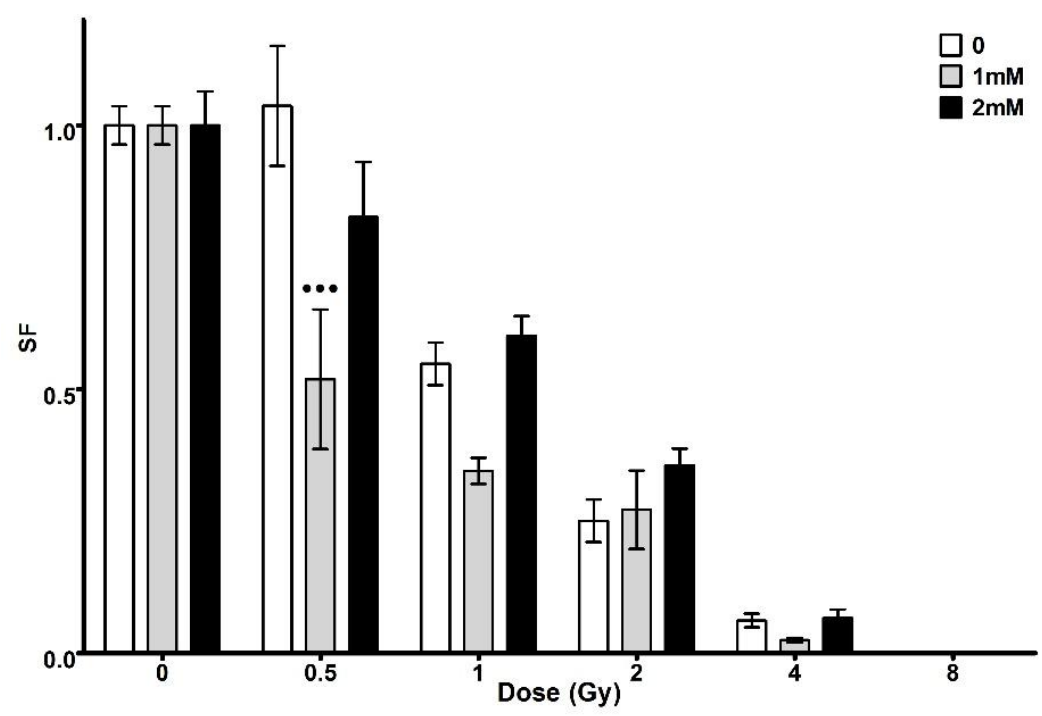

\subsection{Aminoguanidine reduced radiation induced $\mathbf{L D}_{50 \%}$}

Survival fraction data were transformed to obtain dose values in a logarithmic scale and then fitted to a sigmoidal dose-response model as for the $\mathrm{IC}_{50 \%}$ experiments (Figure 8), aiming to observe possible effects of aminoguanidine treatment on $\mathrm{LD}_{50 \%}$ values from irradiated cultures. Relevant coefficients for statistical analysis are in Table I. Data from all groups could be well fitted to model. F-tests found a significant difference $(\mathrm{p}=0.0097)$ between $\log \mathrm{LD}_{50 \%}$ values from untreated and treated with $1 \mathrm{mM}\left(\mathrm{LD}_{50 \%}\right.$ values were 1.207 and $0.5731 \mathrm{~Gy}$, respectively) but no when these groups were compared to $2 \mathrm{mM}(1.278 \mathrm{~Gy})$. The $\mathrm{LD}_{50 \%}$ value of untreated controls was used for set maximum doses for micronucleus frequency assessment experiments as no more than $2 \mathrm{~Gy}$. 
Figure 8: Gamma radiation $L D_{50 \%}$ determination using survival fraction (SF) of cultures untreated or treated with 1 or $2 \mathrm{mM}$ of aminoguanidine and irradiated at indicated doses. Bars in data points represent SEM.

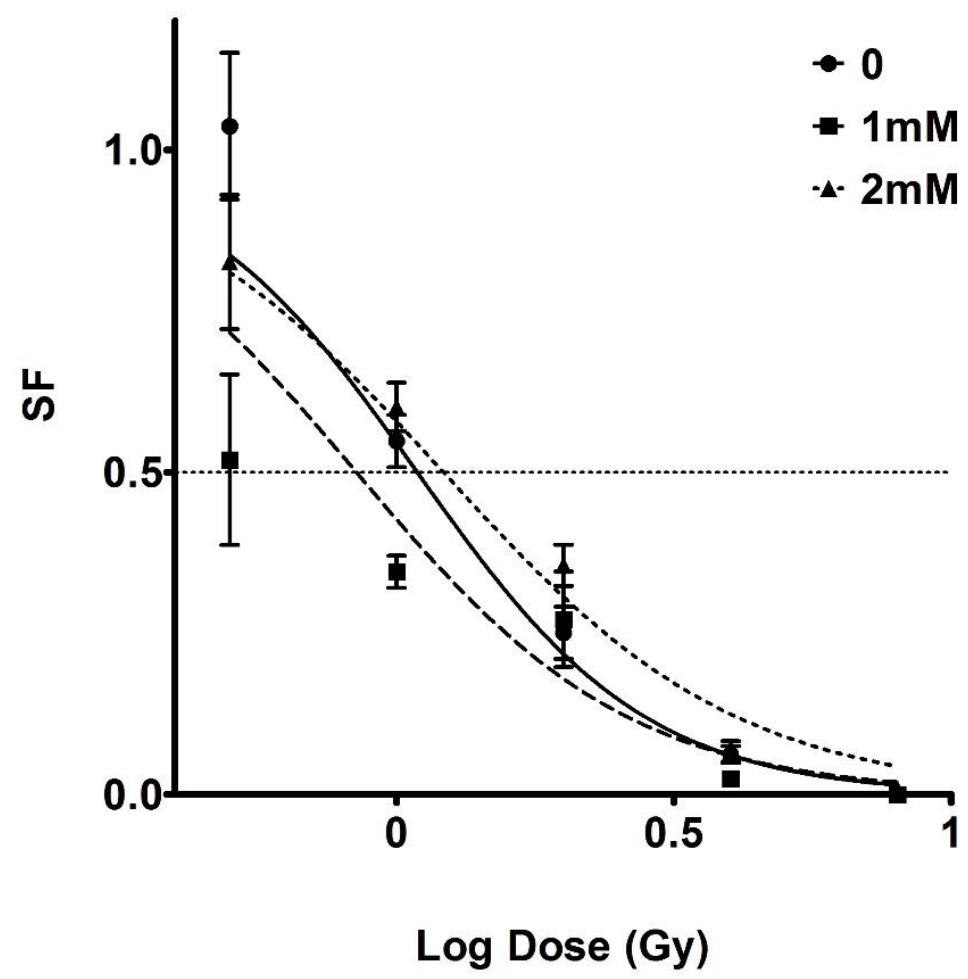

Table I: Goodness of fit $\left(\mathrm{R}^{2}\right), \mathrm{LD}_{50 \%}(\mathrm{~Gy})$ and $\mathrm{Log} \mathrm{LD}_{50 \%}$ and confidence intervals (CI 95\%) obtained from fits of survival fraction data to a sigmoidal dose-response model. Significant differences of $\log \mathrm{LD}_{50 \%}$ values between groups were also observed represented as $\mathrm{p}$ values.

\begin{tabular}{|c|c|c|c|}
\hline & $\mathbf{0}$ & $1 \mathrm{mM}$ & $2 \mathrm{mM}$ \\
\hline $\mathbf{R}^{2}$ & 0.9676 & 0.9275 & 0.9877 \\
\hline $\mathbf{L D}_{\mathbf{5 0 \%}}(\mathbf{G y})$ & 1.207 & 0.5731 & 1.278 \\
\hline CI $95 \%$ & 0.8514 to 1.711 & 0.3127 to 1.050 & 1.027 to 1.591 \\
\hline $\log \mathbf{L D}_{\mathbf{5 0} \%}$ & 0.08171 & -0.2418 & 0.1065 \\
\hline CI $95 \%$ & -0.06984 to 0.2333 & -0.5049 to 0.02138 & 0.01144 to 0.2016 \\
\hline p values & --- & 0.0097 & 0.7014 \\
\hline
\end{tabular}




\section{CONCLUSION}

Altough no dose-dependent effects could be observed regarding its relationship with radiation exposures, aminoguanidine treatment induced changes in cell viability, clonogenic potential and frequency of non-repaired DNA breaks (as micronuclei). It has been reported previously that aminoguanidine has an effect of cell cycle arrest in the G2/M phases in some cell types [29]. Irradiation can also extend duration of S and G2 phases, [30], which turns DNA and thus cells more sensitive to clastogenic effects [31,32] as those caused by ionizing radiations. Treatment with $1 \mathrm{mM}$ increased DNA damage occurrence, as assessed by micronucleus frequency, which may have led to interphasic death in cultures irradiated by $0.5 \mathrm{~Gy}$, and induced loss of clonogenic potential (proliferative death) in cultures irradiated by higher doses, therefore reflecting on a lower $\mathrm{LD}_{50 \%}$ value $(0.5731 \mathrm{~Gy}$, against $1.207 \mathrm{~Gy}$ in controls).

Treatment with $1 \mathrm{mM}$ also induced a prominent reduction of survival fractions in cultures irradiated by $0.5 \mathrm{~Gy}$. Presence of NO in human glioblastoma cells were found to confer resistance to radiation-induced clonogenic death, inhibiting amounts of apoptosis-related proteins [33]. In a macrophagic cell line, NO presence in irradiated cells were found to be a glutathione (GSH) inducer, acting as an anti-oxidant molecule; and as an enhancer of the repair protein DNA-PK (DNA-dependent protein kinase) [34]. In this perspective, the putative reduction of intracellular NO can be related to the increase of genotoxicity and thus, cell death observed in $1 \mathrm{mM}$-treated cultures.

In in vivo experiments, aminoguanidine treatment showed a remarkable antioxidant activity in lung cells [35] and in intestinal crypt cells [36] irradiated with therapeutic doses. Also, aminoguanidine was found to be protective against action of intracellular reactive oxygen species (ROS) in many cell types [37-39]. As elevated ROS levels are related to radiation effects and to an increase on DNA damage [40-43], these properties can explain the reduction of genotoxicity in cells treated with $2 \mathrm{mM}$, and its consequential radio-resistance. Apparently, the $1 \mathrm{mM}$ concentration was sufficient to reduce intracellular NO concentration enough to inhibit the anti-apoptotic and the activity of DNA repair proteins cited above, and $2 \mathrm{mM}$ was sufficient to reduce ROS accumulation, what could lead to cell death. Although also acting 
reducing the mentioned cascades, the last concentration seemed to protect MCF-7 cells from radiation damage. In cultures treated with $2 \mathrm{mM}$ of aminoguanidine, radiation-induced genotoxic damage showed significant reduction comparing to controls, according to a most frequent view of NO presence in irradiated cultures. In this way, NO reduction could lead to a decrease of peroxynitrite formation, and thus reducing frequencies of DNA lesions, assessed by micronucleus frequency test. In an opposite way, aminoguanidine treatment could increase genotoxic damage, and reduced survival fraction and $\mathrm{LD}_{50 \%}$ of breast cancer cells when administered in $1 \mathrm{mM}$ concentration, which could suggest collateral roles of NO production on biological radiation effects in tumor cells.

\section{ACKNOWLEDGEMENT}

The authors would like to thank Eng. Carlos Gaia and Elizabeth Somessari for technical help in irradiation procedures. Fonseca, D.C. and Ocampo, I.Z. were CNPq fellows (120821/2011-7 and 152234/2012-8). The work was supported by IPEN/CNEN-SP.

\section{REFERENCES}

[1] HAN, W. et al., Constitutive nitric oxide acting as a possible intercellular signaling molecule in the initiation of radiation-induced DNA double strand breaks in nonirradiated bystander cells, Oncogene 26 (16) p. 2330-2339 , 2007.

[2] BURKE, A.J., SULLIVAN, F.J., GILES, F.J., GLYNN, S.A., The yin and yang of nitric oxide in cancer progression, Carcinogenesis 34 (3) p. 503-512 , 2013.

[3] KORKMAZ, A., OTER, S., SEYREK, M., TOPAL, T., Molecular, genetic and epigenetic pathways of peroxynitrite-induced cellular toxicity, Interdiscip. Toxicol. 2 (4) p. 219-228, 2009.

[4] MUNTANÉ, J., DE LA MATA, M., Nitric oxide and cancer, World J. Hepatol. 2 (9) p. 337-344, 2010.

[5] YASUDA, H., Solid tumor physiology and hypoxia-induced chemo/radio-resistance: 
Novel strategy for cancer therapy: Nitric oxide donor as a therapeutic enhancer, Nitric Oxide - Biol. Chem. 19 (2) p. 205-216, 2008.

[6] KRUK, J., ABOUL-ENEIN, H.Y., Reactive Oxygen and Nitrogen Species in Carcinogenesis: Implications of Oxidative Stress on the Progression and Development of Several Cancer Types., Mini Rev. Med. Chem. 17 (11) p. 904-919 , 2017.

[7] R AMIN, A., The Metabolomics of Nitric Oxide and Reactive Nitrogen Species in Immune Editing Tumor Milieu: Influence of Nitric Oxide-Modulating Therapies, J. Drug Metab. Toxicol. s8 , 2012.

[8] FITZPATRICK, B., MEHIBEL, M., COWEN, R.L., STRATFORD, I.J., iNOS as a therapeutic target for treatment of human tumors., Nitric oxide Biol. Chem. 19 (2) p. 217-24, 2008.

[9] HANAUE, N. et al., Peroxynitrite formation in radiation-induced salivary gland dysfunction in mice., Biomed. Res. 28 (3) p. 147-51, 2007.

[10] WANG, Y., CHEN, C., LOAKE, G.J., CHU, C., Nitric oxide: Promoter or suppressor of programmed cell death?, Protein Cell 1 (2) p. 133-142, 2010.

[11] CHOWDHURY, P., Aminoguanidine (AG) induces induced both pro- and antioxidant effect in AR42J cells, a rat pancreatic tumor cell line, Ann. Clin. Lab. Sci. 47 (5) p. $572-580,2017$.

[12] ALDERTON, W.K., COOPER, C.E., KNOWLES, R.G., Nitric oxide synthases: structure, function and inhibition., Biochem. J. 357 (Pt 3) p. 593-615, 2001.

[13] WILKES, D.K., DE VRIES, A., OLIVER, D.W., MALAN, S.F., Nitric oxide synthase inhibition by pentacycloundecane conjugates of aminoguanidine and tryptamine, Arch. Pharm. (Weinheim). 342 (2) p. 73-79, 2009.

[14] WARDMAN, P., ROTHKAMM, K., FOLKES, L.K., WOODCOCK, M., JOHNSTON, P.J., Radiosensitization by nitric oxide at low radiation doses., Radiat. Res. 167 (4) p. 475-84, 2007.

[15] MUZALOV, I.I., MIKHAILENKO, V.M., Peculiarities of DNA damage caused by exogenous nitric oxide combined with fractionated low dose ionizing radiation in 
normal and tumor cells., Exp. Oncol. 37 (1) p. 40-3 , 2015.

[16] JORDAN, B.F. et al., Nitric oxide as a radiosensitizer: Evidence for an intrinsic role in addition to its effect on oxygen delivery and consumption, Int. J. Cancer 109 (5) p. $768-773,2004$.

[17] OHTA, S. et al., The role of nitric oxide in radiation damage., Biol. Pharm. Bull. 30 (6) p. 1102-7, 2007.

[18] MATSUMOTO, H. et al., Induction of radioresistance to accelerated carbon-ion beams in recipient cells by nitric oxide excreted from irradiated donor cells of human glioblastoma, Int. J. Radiat. Biol. 76 (12) p. 1649-1657 , 2000.

[19] LUTTJEBOER, M. et al., Strategies for the analysis of in vitro radiation sensitivity and prediction of interaction with potential radiation modifying agents., Int. J. Radiat. Biol. 86 (6) p. 458-66, 2010.

[20] HALL, E.J. et al., Basic radiobiology, Am. J. Clin. Oncol. Cancer Clin. Trials 11 (3) p. $220-252,1988$.

[21] CAVAŞ, T., In vivo genotoxicity of mercury chloride and lead acetate: Micronucleus test on acridine orange stained fish cells., Food Chem. Toxicol. 46 (1) p. 352-8, 2008.

[22] POLARD, T. et al., Giemsa versus acridine orange staining in the fish micronucleus assay and validation for use in water quality monitoring, Ecotoxicol. Environ. Saf. 74 (1) p. 144-149, 2011.

[23] SUN, L.P. et al., Analysis of micronuclei in the transferrin-receptor positive reticulocytes from peripheral blood of nasopharyngeal cancer patients undergoing radiotherapy by a single-laser flow cytometer., J. Radiat. Res. 46 (1) p. 25-35 , 2005.

[24] HEDDLE, J.A., FENECH, M., HAYASHI, M., MACGREGOR, J.T., Reflections on the development of micronucleus assays, Mutagenesis 26 (1) p. 3-10 , 2011.

[25] IAEA, TECHNICAL REPORTS SERIES No. 405 - Cytogenetic Analysis for Radiation Dose Assessment: A Manual, , 2001.

[26] FENECH, M., Cytokinesis-block micronucleus cytome assay, Nat. Protoc. 2 (5) p. 
1084-1104, 2007.

[27] SU, X. et al., Biphasic Effects of Nitric Oxide Radicals on Radiation-Induced Lethality and Chromosome Aberrations in Human Lung Cancer Cells Carrying Different p53 Gene Status, Int. J. Radiat. Oncol. Biol. Phys. 77 (2) p. 559-565 , 2010.

[28] ABDELMAGID, S.A., TOO, C.K.L., Prolactin and estrogen up-regulate carboxypeptidase-D to promote nitric oxide production and survival of MCF-7 breast cancer cells, Endocrinology 149 (10) p. 4821-4828, 2008.

[29] TAKASHI, S., HIDEYO, S., MASAAKI, N., KENICHI, M., Aminoguanidine inhibits cell proliferation by prolongation of the mitotic phase, Toxicol. Lett. 69 (3) p. 273-278 , 1993.

[30] TSUCHIDA, E. et al., Effect of X-irradiation at different stages in the cell cycle on individual cell-based kinetics in an asynchronous cell population, PLoS One 10 (6) p. $1-17,2015$.

[31] GIUNTA, S., BELOTSERKOVSKAYA, R., JACKSON, S.P., DNA damage signaling in response to double-strand breaks during mitosis, J. Cell Biol. 190 (2) p. 197-207, 2010.

[32] ORTHWEIN, A. et al., Mitosis inhibits DNA double-strand break repair to guard against telomere fusions, Science (80-. ). 344 (6180) p. 189-193, 2014.

[33] MATSUMOTO, H., TAKAHASHI, A., OHNISHI, T., Nitric oxide radicals choreograph a radioadaptive response, Cancer Res. 67 (18) p. 8574-8579 , 2007.

[34] TOKUZUMI, S., HORI, M., MONOBE, M., HOSOI, Y., KOJIMA, S., Effect of nitric oxide on gamma-ray-induced micronucleus frequency in RAW264.7 cells, Radiat Res 164 (6) p. 723-732, 2005.

[35] EROGLU, C. et al., Aminoguanidine ameliorates radiation-induced oxidative lung damage in rats, Clin. Investig. Med. 31 (4) , 2008.

[36] HUANG, E.Y., WANG, F.S., LIN, I.H., YANG, K.D., Aminoguanidine Alleviates Radiation-Induced Small-Bowel Damage Through Its Antioxidant Effect, Int. J. Radiat. Oncol. Biol. Phys. 74 (1) p. 237-244 , 2009. 
[37] PINTUS, E., KADLEC, M., JOVIČIĆ, M., SEDMÍKOVÁ, M., ROS-SANTAELLA, J., Aminoguanidine Protects Boar Spermatozoa against the Deleterious Effects of Oxidative Stress, Pharmaceutics 10 (4) p. 212 , 2018.

[38] LYONS, T.J. et al., Cultured Retinal Capillary Cells, 41 (5) p. 1176-1180 , 2018.

[39] MOHSEN, A., FARHAD, G.S., MOHAMMAD-REZA, J., Effect of aminoguanidine on sciatic functional index, oxidative stress, and rate of apoptosis in an experimental rat model of ischemia-reperfusion injury., Can. J. Physiol. Pharmacol. 92 (12) p. 1013 $1019,2014$.

[40] CADET, J., WAGNER, J.R., DNA Base Damage by Reactive Oxygen Species, Oxidizing Agents, and UV Radiation, Cold Spring Harb. Perspect. Biol. 5 (2) p. a012559-a012559, 2013.

[41] AZZAM, E.I., JAY-GERIN, J.-P., PAIN, D., Ionizing radiation-induced metabolic oxidative stress and prolonged cell injury, Cancer Lett. 327 (1-2) p. 48-60 , 2012.

[42] MCADAM, E., BREM, R., KARRAN, P., Oxidative Stress-Induced Protein Damage Inhibits DNA Repair and Determines Mutation Risk and Therapeutic Efficacy, Mol. Cancer Res. 14 (7) p. 612-622, 2016.

[43] LOMAX, M.E., FOLKES, L.K., O’NEILL, P., Biological consequences of radiationinduced DNA damage: Relevance to radiotherapy, Clin. Oncol. 25 (10) p. 578-585, 2013. 